Supporting Information

\title{
Part 1: Cost Analysis of Carbon Capture and Storage from U.S. Natural Gas-fired Power Plants
}

Peter Psarras ${ }^{1}$, Jiajun He ${ }^{2}$, Hélène Pilorgél, Noah McQueen ${ }^{1}$, Alexander Jensen-Fellows ${ }^{1}$, Kourosh Kian' ${ }^{1}$ Jennifer Wilcox ${ }^{1}$

${ }^{1}$ Department of Chemical Engineering, Worcester Polytechnic Institute, Worcester, MA

${ }^{2}$ Department of Mechanical Science and Engineering, University of Illinois, Urbana, IL

\section{KEYWORDS}

Carbon capture, avoided emissions, natural gas combined cycle (NGCC) 


\section{Cost Model: Baseline Assumptions}

Table S1 outlines the baseline assumptions used in base case cost model, as well as the three configurations considered in this study. Variations in cost parameters are described below. All costs reported in constant USD 2017.

Table S1. Cost parameters used for the four cases under study. Variations occur due to changes in input $\mathrm{CO}_{2}$ concentration and heat source quality.

\begin{tabular}{|l|c|}
\hline Parameter & Value \\
\hline IECM values & \\
CONFIGURE SESSION & NGCC \\
Plant type & Typical new plant \\
Configuration & amine system \\
MEA Scrubber & wet cooling tower \\
Water and solids management & set to region of interest \\
Plant Location & \\
PERFORMANCE & set to desired output $(1-5)$ \\
Number of turbines & $75 \%$ \\
Capacity factor & \\
REGULATIONS AND TAXES & $90 \%$ \\
Total CO ${ }_{2}$ removal constraint & \\
FINANCING AND COST YEAR & 2017 \\
Year costs reported? & constant \\
Constant or current dollars & $7.09 \%$ \\
Discount rate (before taxes) & $11.28 \%$ \\
Fixed charge factor & 30 years \\
Plant life & \\
FUEL & FG + \\
Natural gas cost & NO \\
GAS TURBINE PERFORMANCE & $129.6 \$ \mathrm{mscm}$ \\
Gas turbine model & \\
RETROFIT ADJUSTMENT FACTORS & \\
All values & \\
CO ${ }_{2}$ CAPTURE, TRANSPORT, AND STORAGE & \\
System used & \\
CO ${ }_{2}$ product compressor used? & \\
\hline
\end{tabular}




\section{Compression and Trucking}

Due to the smaller volumes of $\mathrm{CO}_{2}$ delivered in this analysis, refrigerated tanker trucking was selected as the mode of transport. This entails compression to approximately 1.7 MPa. The costing method is detailed meticulously in the work of McCollum and Ogden. ${ }^{1}$ A 5-stage compressor train with dehydration and inter-stage cooling is employed to prepare the $\mathrm{CO}_{2}$ stream for trucking transport $\left(1.7 \mathrm{MPa}\right.$ and $\left.-30^{\circ} \mathrm{C}\right)$. The inlet temperature at each stage is $343 \mathrm{~K}$ with compression ratio of 1.76 and isoentropic efficiency 0.75 . Cooling to final transport temperature is achieved at $16.5 \mathrm{kWh} / \mathrm{tCO}_{2}$. The trucking model is based on the work of Berwick and Farooq ${ }^{2}$, and outlined in detail by Psarras and collaborators. ${ }^{3}$ It takes as inputs the overall volume of $\mathrm{CO}_{2}$ to be delivered per route and total distance per route.

\section{Learning through $\mathrm{CO}_{2}$-EOR}

Natural $\mathrm{CO}_{2}$ fields provide the main source of $\mathrm{CO}_{2}$ for current $\mathrm{CO}_{2}$-EOR projects in the U.S. ( $\sim 55 \mathrm{Mt} \mathrm{CO} 2$ per year). Roughly $80 \%$ of the $\mathrm{CO}_{2}$ used for $\mathrm{CO}_{2}$-EOR activities in the U.S. comes from four major natural $\mathrm{CO}_{2}$ fields, i.e., Jackson Dome, Sheep Mountain, McElmo Dome, and Bravo Dome. The remainder of the $\mathrm{CO}_{2}$ used for $\mathrm{CO}_{2}$-EOR projects (approximately $17 \mathrm{Mt} \mathrm{CO}_{2}$ per year) is supplied from anthropogenic sources as previously discussed. ${ }^{4}$ The costs of producing $\mathrm{CO}_{2}$ from these natural sources is associated primarily with compression and pipeline transport. For tanker delivery, liquefied $\mathrm{CO}_{2}$ is stored in cryogenic vessels and transported by tanker trucks with capacity ranging from 2 to 30 tonnes and $\mathrm{CO}_{2}$ compressed to $1.7 \mathrm{MPa}$ at $-30{ }^{\circ} \mathrm{C}$, which costs approximately $\$ 6 / \mathrm{tCO}_{2}$. On the order of $100 \mathrm{~s}$ to $1000 \mathrm{~s}$ of $\mathrm{ktCO}_{2} / \mathrm{yr}$ transport, trucking costs are approximately $\$ 0.14 /$ tonne-mile. When considering loads greater than $750 \mathrm{ktCO}_{2} / \mathrm{yr}$, pipeline transport becomes more economical at approximately $\$ 0.07 /$ tonne-mile. Based upon the current model, pipeline transport of $\mathrm{CO}_{2}$ requires compression ranging from 9-15 $\mathrm{MPa}$ and temperatures between $10-35^{\circ} \mathrm{C}$, at an approximate cost of $\$ 8 / \mathrm{tCO}_{2} \cdot{ }^{3,5}$ The existence of these natural sources

combined with the demand of $\mathrm{CO}_{2}$ for EOR, provided the economic incentive to establish the majority of the $\mathrm{CO}_{2}$ pipelines that exist in the U.S. today.

Enhanced oil recovery has been a commercial activity for nearing 50 years, with the first successful pilot-scale tests taking place in Texas in the early 1960s. ${ }^{6}$ Based upon EOR activities and subsequent experience in the U.S., EOR using $\mathrm{CO}_{2}$ has shown to increase the recovery of the 
original oil in place by up to $15 \% .^{7}$ The way in which EOR is carried out in the U.S. today would not be considered negative or neutral since roughly $80 \%$ of the $\mathrm{CO}_{2}$ used for EOR is sourced naturally from $\mathrm{CO}_{2}$ that has been stored in the earth for millions of years, not unlike the oil and gas that are being recovered. Table S2 $2^{4,8}$ shows the volumes and sources of natural- versus anthropogenic-sourced $\mathrm{CO}_{2}$ used for the various EOR projects in the U.S. today.

Table S2. Volume and source of $\mathrm{CO}_{2}$ injected for EOR projects in the U.S. (adapted from ${ }^{4,8}$ )

\begin{tabular}{cccc}
\hline Location & $\mathbf{C O}_{2}$ source type & \multicolumn{2}{c}{$\mathbf{C O}_{2}$ supply (MMscfd) } \\
& & Natural & Anthropogenic \\
\hline Texas/Utah/New & Geologically stored & 1730 & 335 \\
Mexico/Oklahoma & Natural gas processing & 1100 & - \\
Mississippi/Louisiana & Geologically stored & - & 340 \\
Colorado/Wyoming & Natural gas processing & - & 15 \\
Michigan & Ammonia plant & - & 30 \\
Oklahoma & Fertilizer plant & - & 150 \\
Saskatchewan & Coal gasification & 2830 & 870 \\
\hline Total (MMscfd) & & 55 & 17 \\
Total (Mt/year) & & & a
\end{tabular}

${ }^{a} \mathrm{MMscfd}$ can be converted to $\mathrm{Mt} \mathrm{CO}_{2}$ per year by first multiplying by 365 (days per year) and then dividing by 18.9 Mscf per metric ton

In particular for MS-EOR, the net $\mathrm{CO}_{2}$ utilization is $0.9 \mathrm{tCO}_{2} / \mathrm{bbl}$ of oil recovered with an incremental increase in oil recovery by $13 \%$. Work of Hovorka (2013), ${ }^{9}$ has shown that this level of storage may be possible by using $\mathrm{CO}_{2}$ in a once-through system rather than recycling it, which is similar to the "stacked storage" approach used when injecting $\mathrm{CO}_{2}$ into a saline aquifer. Although the costs that $\mathrm{CO}_{2}$-EOR producers typically pay for $\mathrm{CO}_{2}$ is proprietary, it has been well established that it is tied to oil prices and are generally found to be in the range of several dollars per thousand standard cubic feet (Mscf). At oil prices of $\$ 70 / \mathrm{bbl}$, it has been reported that contracts were priced at $\$ 30 / \mathrm{tCO}_{2} \cdot{ }^{10}$ Also, the $\mathrm{CO}_{2}$-EOR producers who own the geologic formations that naturally store $\mathrm{CO}_{2}$ (e.g., Denbury Resources, Kinder Morgan, and Occidental Petroleum), pay significantly less for the $\mathrm{CO}_{2}$, i.e., several U.S. dollars per tonne at comparable oil prices. ${ }^{11}$ 


\section{Geological Sequestration}

Ideal reservoirs are typically located at depths greater than $1 \mathrm{~km}$ in the earth in order to maintain the $\mathrm{CO}_{2}$ in its supercritical phase, and are comprised of porous rocks such as sandstone, limestone and dolomite, or mixtures thereof. The pore space of these reservoirs is filled by salty water, oil, or gas, which are denser than supercritical $\mathrm{CO}_{2}$. The prevention of leakage thus requires the presence of a cap rock made of low permeability rocks, such as shale, anhydrite or low permeability carbonates. Ideal sequestration sites also require favorable geo-mechanical conditions to prevent reservoir or seal fracturing during injection, suitable conditions for monitoring, low likelihood of affecting groundwater, and compatibility with existing land and resource use.

Data regarding $\mathrm{CO}_{2}$ storage were provided by the USGS Assessment of Geologic Carbon Storage Resources in the U.S. The capacity of each basin is the mean technically accessible $\mathrm{CO}_{2}$ storage resource provided on the USGS website. Further details for the capacity calculation are provided in USGS reports. ${ }^{12}$ Each basin is composed of one or several Storage Assessment Units (SAU), that can overlap geographically at different depths. The USGS defines SAUs as a "mappable volume of rock that consist of a porous reservoir." These porous reservoirs are sedimentary formations made of siliciclastic and carbonate rocks. The USGS identified 186 SAUs in 34 basins in the contiguous U.S. among which 176 SAUs in 31 basins have quantitative data. The dataset of quantitative SAUs includes the depth of the unit, its thickness $h$, its porosity $\emptyset$ and its permeability $k$. From these parameters provided by USGS and the parameters provided by Baik et al., 2018 ${ }^{12,13}$ (Table S3), the injectivity $Q_{\max }$ of each SAU was calculated using a radial Darcy's law for single-phase flow. ${ }^{14}$

$$
\begin{gathered}
\mathrm{Q}_{\max }=\frac{2 \pi k h \Delta P_{\max }}{\mu \log \left(\frac{r_{e}}{r_{w}}\right)}, \text { with } \mathrm{r}_{\mathrm{e}}=\sqrt{\frac{2 k T}{\emptyset \mu C}} \\
\Delta \mathrm{P}_{\max }=\rho g d \alpha
\end{gathered}
$$


Table S3. Parameters used for injection capacity estimation and pressure calculation ${ }^{13}$

\begin{tabular}{|c|l|c|c|}
\hline Parameter & \multicolumn{1}{|c|}{ Description } & Nominal value & Units \\
\hline $\mathrm{Q}$ & Volumetric injection rate & Site-specific & $\mathrm{m}^{3} \cdot \mathrm{s}^{-1}$ \\
\hline $\mathrm{k}$ & Permeability of the formation & Site-specific & $\mathrm{m}^{2}$ \\
\hline $\mathrm{h}$ & Thickness of porous region in formation & Site-specific & $\mathrm{m}$ \\
\hline$\Delta \mathrm{P}_{\max }$ & Pressure buildup at the injection well & Site-specific & $\mathrm{Pa}$ \\
\hline$\mu$ & Dynamic viscosity of water & $5.8 \times 10^{-4}\left(\right.$ at $\left.\sim 47^{\circ} \mathrm{C}\right)$ & $\mathrm{Pa} \cdot \mathrm{s}$ \\
\hline $\mathrm{T}$ & Time frame for injection & $30 \mathrm{yr}\left(=9.5 \times 10^{8} \mathrm{~s}\right)$ & $\mathrm{S}$ \\
\hline$\varnothing$ & Porosity of formation & Site-specific & - \\
\hline $\mathrm{C}$ & Compressibility of rocks & $1 \times 10^{-9}$ & $\mathrm{~Pa}^{-1}$ \\
\hline $\mathrm{r}_{\mathrm{e}}$ & Radius of pressure influence & Site-specific & $\mathrm{m}$ \\
\hline $\mathrm{r}_{\mathrm{w}}$ & Tubing radius of the injection well & 0.1 & $\mathrm{~m}$ \\
\hline$\rho$ & Density of water & 1,000 & $\mathrm{~kg} \cdot \mathrm{m}^{-3}$ \\
\hline $\mathrm{g}$ & Acceleration of gravity & 9.81 & $\mathrm{~m} \cdot \mathrm{s}^{-2}$ \\
\hline $\mathrm{d}$ & Depth to center of formation & Site-specific & $\mathrm{m}$ \\
\hline$\alpha$ & Maximum allowable pressure differential & 0.5 & - \\
\hline
\end{tabular}

The calculation of the pressure gradient $\Delta \mathrm{P}_{\max }$, assumes a $50 \%$ allowable pressure increase at the well bore $(\alpha=0.5)$. The $\mathrm{CO}_{2}$ injection wells are classified as class VI wells by the Environmental Protection Agency. The maximum injection pressure allowed for this type of well is $90 \%$ of the fracture pressure of the subsurface. The hydrostatic pressure gradient used in this study is about $10 \mathrm{MPa} / \mathrm{km}$ so the maximum pressure increase at the borehole is $5 \mathrm{MPa} / \mathrm{km}$, corresponding to $90 \%$ of $5.5 \mathrm{MPa} / \mathrm{km}$. The fracture gradient in this study is thus $15.5 \mathrm{MPa} / \mathrm{km}$ and corresponds to the lower end of the common fracture gradient range from $14 \mathrm{MPa} / \mathrm{km}$ to 23 $\mathrm{MPa} / \mathrm{km} .{ }^{15}$

The injectivity of each basin on the Figure S1 was calculated by averaging the injectivities of its SAU weighted by the volume of each SAU. The data for the $\mathrm{CO}_{2}$ pipeline network were obtained from the Stanford University's Digital Repository. ${ }^{16}$ Each basin contains several reservoirs called Storage Assessment Units (SAUs), that can geographically overlap each other at different depths. The USGS provides numerous parameters for each SAU including, depth, thickness, porosity, and permeability. Using the method described in Baik et al., 2018, the injectivities were calculated for each SAU. The results range from $23 \mathrm{ktCO}_{2} / \mathrm{yr}$ for the Eastern Mesozoic Rift Basin under New Jersey and Pennsylvania to $138,000 \mathrm{ktCO}_{2} / \mathrm{yr}$ for the Los Angeles Basin under California (Figure $\mathrm{S} 1$ ). Based on the work of Baik et al. (2018), injectivities below $250 \mathrm{ktCO}_{2} / \mathrm{yr}$ are not suitable for injection due to risks associated with demonstration-scale injection of $\mathrm{CO}_{2}$ into low-injectivity reservoirs. The Eastern Mesozoic Rift, Paradox, Uinta and Piceance, Eastern Great, Black Warrior 
and Kansas basins are therefore discarded from the potential basins for injection. Uinta and Piceance basins have global injectivities lower than $250 \mathrm{ktCO}_{2} / \mathrm{yr}$, but some of their SAUs are still over this limit and could be used for $\mathrm{CO}_{2}$ storage (Figure 3 from manuscript). Overall of the basins considered in the contiguous U.S., $103 \mathrm{SAU}$ are above the $250 \mathrm{ktCO}_{2}$ cut-off and may be suitable for $\mathrm{CO}_{2}$ injection. If one were to drill only one well in each of the $\mathrm{SAUs}$ with $\mathrm{CO}_{2}$ injection at maximum injectivity, the contiguous U.S. would have the ability of storing roughly $2 \mathrm{GtCO}_{2} / \mathrm{yr}$ or $40 \%$ of the annual emissions of the U.S. (2018 US CO 2 emissions $\sim 5.3 \mathrm{Gt}$ ).

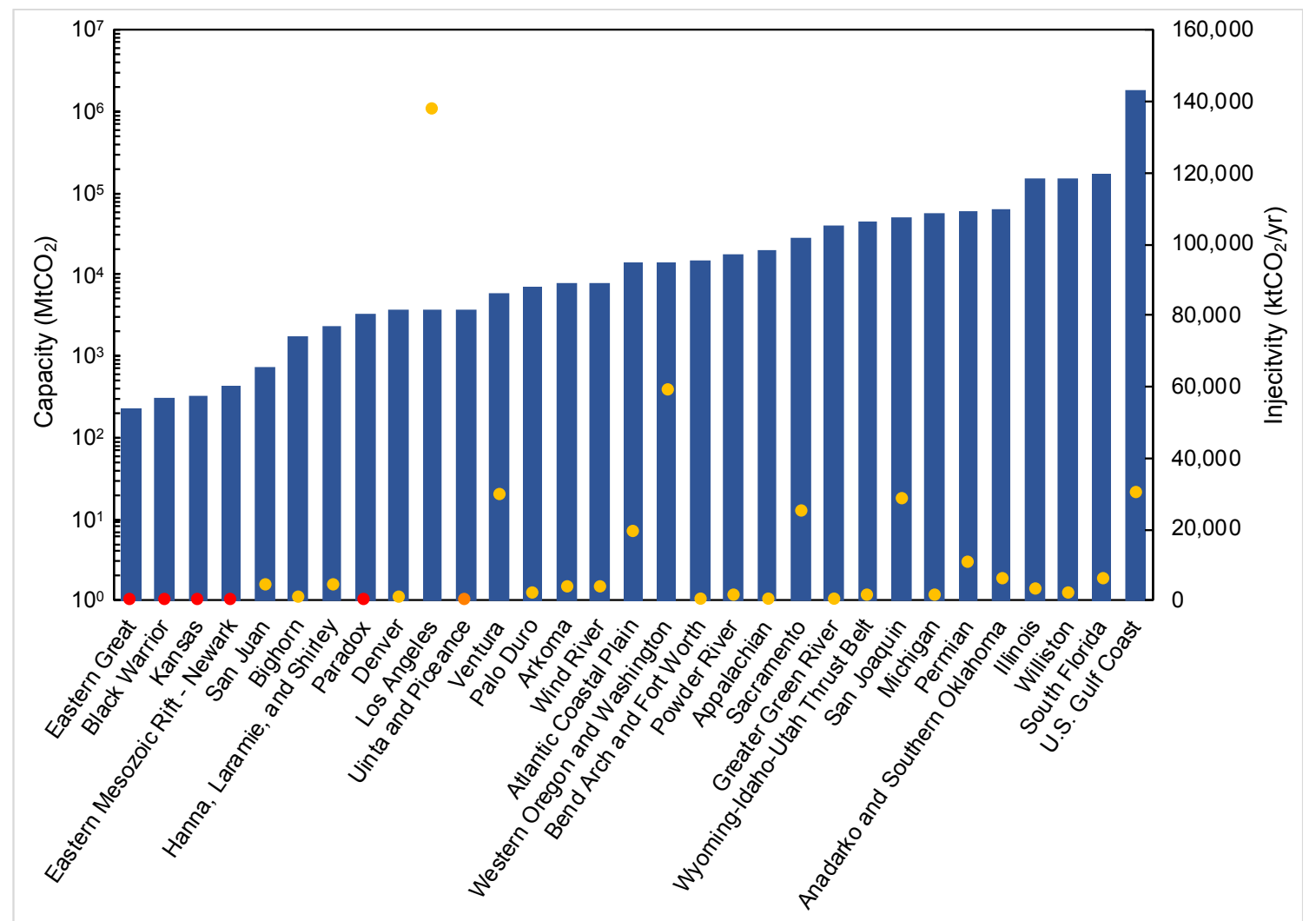

Figure S1. Capacity and injectivity of $\mathrm{CO}_{2}$ in reservoirs assessed by the USGS for $\mathrm{CO}_{2}$ sequestration in the contiguous U.S. Blue bars represent the capacity of each reservoir in $\mathrm{MtCO}_{2}$. Dots represent the injectivity of $\mathrm{CO}_{2}$ in $\mathrm{ktCO}_{2} / \mathrm{yr}$. The basins with injectivities over the cut-off of $250 \mathrm{ktCO}_{2}$ are represented by the yellow dots, while those with injectivities below the cut-off are represented by the red dots, and the orange dot represents the basin with global injectivity below the cut-off but with injectivity over the cut-off for at least one SAU. 


\section{Trucking Transportation is the Most Cost-Effective for Scales $<500 \mathrm{ktCO}_{2} / \mathrm{yr}$}

While large scale $\mathrm{CO}_{2}$ transport is dominated by pipeline, transport economics begin to favor trucking at less than $500 \mathrm{ktCO}_{2} / \mathrm{yr}^{3}$ Since this describes the range of $\mathrm{CO}_{2}$ output for the DAC plants considered in this study, trucking is selected as the mode of choice for transport between DAC plants and various end uses. A modal optimization (i.e., cluster identification and hub stationing) is not performed in this analysis but could be of use to identify ideal locations for infrastructure development. ${ }^{17}$ The trucking model is based largely on the work of Berwick and Farooq (2003), ${ }^{2}$ using updated fuel emission intensities, fuel costs, and labor costs. Liquefaction costs are assumed in the DAC plant capital and operating expenses, assuming conditions of 1.7 $\mathrm{MPa}$ and $-30{ }^{\circ} \mathrm{C} .{ }^{5}$ Source-end use distances were obtained by performing an origin-destination distance matrix over a U.S. street network dataset. This set of distances together with the estimated $\mathrm{CO}_{2}$ demand for each end use served as model inputs.

Trucking transport costs are controlled mainly by two factors: hauling capacity and distance traveled. At very low volumes ( $\sim 5 \mathrm{ktCO}_{2} / \mathrm{yr}$ and below) costs are dominated by trucking lease or purchasing as hauling remains well below capacity. As delivery closes in on maximum capacity per truck (here constrained to 100,000 miles total travel per year), economies of scale are optimized, and costs are minimized. Figure S2 shows how increased load affects costs at fixed distance hauls of 20, 50 and 100 miles (one-way).

Maximum hauling payload per delivery is set at 20 tonnes $\mathrm{CO}_{2}$. The number of roundtrips required is obtained by dividing the total volume to be delivered by the maximum payload. This factor, termed payloads, determines all variable operating expenses. For fuel consumption, a cost of $\$ 0.3166$ per mile is applied for the full truck (pre-delivery) and $\$ 0.2468$ per mile for postdelivery transit. Labor costs are calculated at $\$ 20 / \mathrm{hr}$ and include time traveled, assuming an average speed of 38 miles per hour, and accounting for an additional hour in waiting time during $\mathrm{CO}_{2}$ transfer from truck to on-site storage tanks (the cost of storage tanks and any associated onsite piping is not included in the model and assumed to be incurred by the host). Tire replacement and general vehicle maintenance is calculated at $\$ 0.0477$ and $\$ 0.886$ per mile traveled, respectively. The refrigerated tanker purchase price is $\$ 175,000$ and is serviceable for 5 years, with a hard-constrain of 100,000 miles traveled per year. Additional trucks must be added to the fleet for transport demands in excess of 100,000 miles total travel. 


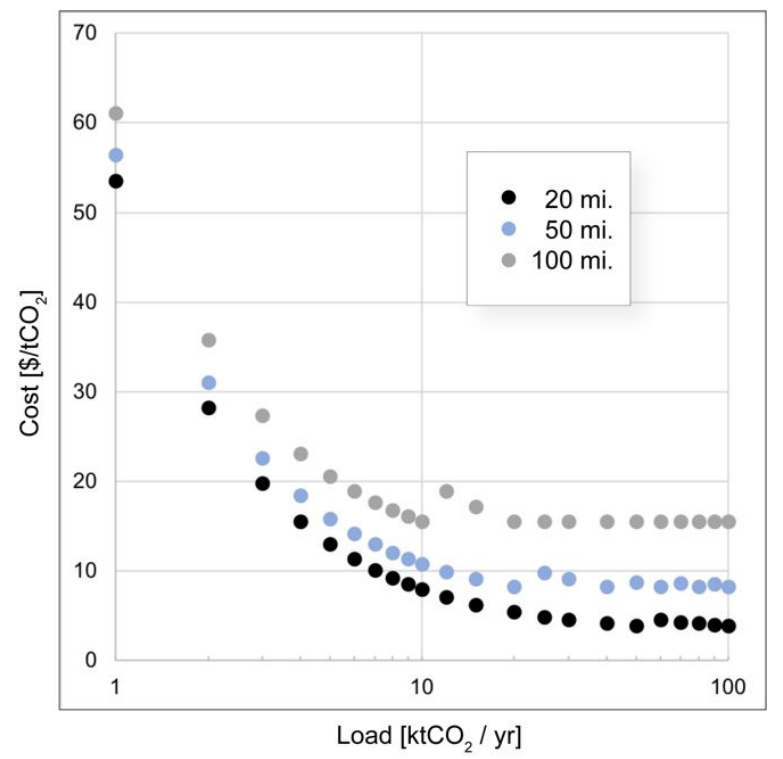

Figure S2. Cost of trucking transport as a function of load at fixed-distance hauls $(20,50$, and 100 miles). At low volumes, costs are dominated by truck lease and purchasing. Costs converge to a minimum as hauling approaches capacity, where small cost bumps reflect the addition of trucks as justified by model constraints.

\section{REFERENCES}

(1) McCollum, D. L.; Ogden, J. M. Techno-Economic Models for Carbon Dioxide Compression, Transport, and Storage \& Correlations for Estimating Carbon Dioxide Density and Viscosity; 2006.

(2) Berwick, M.; Farooq, M. Truck Costing Model for Transportation Managers; 2003; Vol. MPC Report.

(3) Psarras, P. C.; Comello, S.; Bains, P.; Charoensawadpong, P.; Reichelstein, S.; Wilcox, J. Carbon Capture and Utilization in the Industrial Sector. Environ. Sci. Technol. 2017, 51 (19), 11440-11449.

(4) Kuuskraa, V. A.; Van Leeuwen, T.; Wallace, M.; DiPietro, P. Improving Domestic Energy Security and Lowering $\mathrm{CO}_{2}$ Emissions with "next Generation" $\mathrm{CO}_{2}$-Enhanced Oil Recovery ( $\mathrm{CO}_{2}$-EOR). In National Energy Technology Laboratory, Pittsburgh, PA, USA; 2011.

(5) Wilcox, J. Carbon Capture; Springer Science \& Business Media, 2012.

(6) Holm, W. L. Evolution of the Carbon Dioxide Flooding Processes. J. Pet. Technol. 1987, 39 (11), 1337-1342.

(7) International Energy Agency (IEA). Resources to Reserves 2013: Oil, Gas and Coal Technologies for the Energy Markets of the Future; 2013. 
(8) Kuuskraa, V.; Wallace, M. $\mathrm{CO}_{2}$-EOR Set for Growth as $\mathrm{New}_{\mathrm{CO}_{2}}$ Supplies Emerge. Oil Gas J. 2014, 112 (5), 92-112.

(9) Hovorka, S. D. CCU\&S via Stacked Storage - Case Studies from $\mathrm{CO}_{2}$-EOR Basins of the United States. Energy Procedia 2013, 37, 5166-5171.

(10) Bliss, K.; Eugene, D.; Harms, R.; Carillo, V.; Coddington, K.; Moore, M.; Harju, J.; Jensen, M.; Botnen, L.; Marston, P.; et al. A Policy, Legal, and Regulatory Evaluation of the Feasibility of a National Pipeline Infrastructure for the Transport and Storage of Carbon Dioxide; 2010.

(11) International Energy Agency (IEA). World Energy Outlook; 2015.

(12) U.S. Geological Survey (USGS). National Assessment of Geologic Carbon Dioxide Storage Resources https://pubs.usgs.gov/ds/774/ (accessed Feb 20, 2019).

(13) Baik, E.; Sanchez, D. L.; Turner, P. A.; Mach, K. J.; Field, C. B.; Benson, S. M. Geospatial Analysis of Near-Term Potential for Carbon-Negative Bioenergy in the United States. Proc. Natl. Acad. Sci. 2018, 115 (13), 3290-3295. https://doi.org/10.1073/pnas.1720338115.

(14) Nicot, J. P.; Hosseini, S. A.; Solano, S. V. Are Single-Phase Flow Numerical Models Sufficient to Estimate Pressure Distribution in $\mathrm{CO}_{2}$ Sequestration Projects? Energy Procedia 2011, 4, 3919-3926.

(15) Michael, K.; Neal, P. R.; Allinson, G.; Ennis-King, J.; Hou, W.; Paterson, L.; Sharma, S.; Aiken, T. Injection Strategies for Large-Scale $\mathrm{CO}_{2}$ Storage Sites. Energy Procedia 2011, 4, 4267-4274.

(16) Hart Energy Publishing. Carbon dioxide $\left(\mathrm{CO}_{2}\right)$ pipelines in the United States purl.stanford.edu/yf510bb3744.

(17) Sanchez, D. L.; Johnson, N.; McCoy, S. T.; Turner, P. A.; Mach, K. J. Near-Term Deployment of Carbon Capture and Sequestration from Biorefineries in the United States. Proc. Natl. Acad. Sci. 2018, 115 (19), 4875-4880. 